nitrided wires treated in the same way as those to which Curve No. 2 of our previous letter relates are reduced in hydrogen, say, at $1,000^{\circ} \mathrm{C}$., they revert entirely to a stage which is identical with that represented in Curve No. 1. There is no yield. On the other hand, if wires are heated in the same manner as in that of Curve No. 2, the only difference being that the second treatment at $1,300^{\circ} \mathrm{C}$., continued for $20 \mathrm{sec}$, is carried out in hydrogen instead of nitrogen, the resulting wire is exactly like that of Curve No. 1. Again there is no yield.

If, during nitriding, changes in the crystal structure are also taking place, the conditions are somewhat more complicated, and the behaviour of the wire is then dependent on the resulting erystal size as well as on the quantity and distribution of nitrogen sorbed. PaUL Tứry. STePhen Krausz.

Research Laboratory,

United Incandescent Lamp and

Electrical Co., Ltd.,

Ujpest, near Budapest.

Nov. 16.

${ }^{1}$ Nature, 138, 760 (Oct. 31, 1936).

2 Túry, P., and Krausz, S., Nature, 138, 331 (Aug. 22, 1936).

\section{Water and Fat Contents of Tsetse Flies}

A CONSIDERABLE amount of work has recently been carried out or is in progress concerning the physiological responses of tsetse flies to environmental conditions. These studies have been largely concerned with the effect on the water and fat content of the flies.

There is a point to which attention may be directed as it has not been taken into consideration in any paper of the above nature which has as yet come to my hand. In estimating the water content, it seems to be the practice to utilize the gross wet and gross dry weights of the flies. It is to be pointed out, however, that the ether soluble 'fat' contains no water, and is very variable in quantity in different circumstances. It is obvious that, with the same quantity of water, the water content, expressed as percentage of the wet weight, will vary inversely with the fat content.

In the course of our work with Glossina morsitans, one hundred and fifty unfed flies, killed within two hours of emergence, have furnished a mean water content, based on gross weights, of 70.8 per cent. If the weight of the 'fat', the mean of which is near $1.70 \mathrm{mgm}$, is subtracted from both wet and dry weights, however, the mean water content is $76 \cdot 4$ per cent. There is practically no difference between the sexes in this connexion.

The distribution of the respective percentage water contents shows the following ranges in round figures:

(1) With 'fat' included : 66-74 per cent.

(2) With 'fat' excluded: 72-79 per cent.

Unfed flies which have been under starvation for any considerable period have naturally consumed a large portion of their fat reserve, and the loss of fat tends to raise the final percentage of water if the latter is reckoned on gross wet and dry weights. On this basis, in fact, it may appear that no significant disturbance of the water balance has taken place during an experiment, whereas if the 'fat' is excluded a significant difference may be revealed.

A single instance will illustrate this point. A group of unfed flies, which had been exposed to certain conditions, returned the following mean figures:

$$
\begin{array}{ll}
\text { Wet woight } & 19.6 \mathrm{mgm} \text {. } \\
\text { Dry ," } & 5.7 \mathrm{mgm} \text {. } \\
\text { 'Fat' ", } & 0.60 \mathrm{mgm} \text {. }
\end{array}
$$

Using gross weights, the proportion of water is 70.9 per cent, practically the mean of the control. Excluding the 'fat', the proportion of water is 73.2 per cent, which is definitely below the mean of the control calculated on the same basis. Tested by $t$, this result has bcen found to be statistically significant.

One further point is rather obvious, namely, that, in the case of an insect containing in the first place 70-76 per cent of its weight in water, a considerable loss of actual water is not very conspicuously reflected in the final ratio between wet and dry weights. As this is merely a matter of simple arithmetic, I will not enlarge upon the point beyond remarking that the fact adds importance to relatively small differences in the ratios recorded.

Department of Agriculture,

RUPERT W. JACK (Chief Entomologist.)

$$
\begin{aligned}
& \text { P.O. Box } 387, \\
& \text { Salisbury, }
\end{aligned}
$$

Southern Rhodesia.

\section{Four Molluscs rarely recorded from the Red Sea}

As an example of the way in which the distribution of marine animals is complicated by ecological factors, I quote four species of nudibranch mollusc, all of which are large and conspicuous, and which, though common in Zanzibar, have been rarely recorded from the Red Sea. I have myself only lately seen specimens, though twenty-three out of the last thirty-five years have been spent on this coast :

Asteronotus hemprichi Ehr. One specimen on Sudan coast, 1905; one specimen by Dolfuss, in Gulf of Suez, 1927-29; two here in 1934 .

Chromodoris (Glossodoris) annulata Eliot, fairly large for its genus and so strikingly marked that if seen it could not be missed. Colour white with distinct yellow spots. Mantle border violet, with large rings of the same on the back, one enclosing the rhinophores, the other the gills. None seen until 1934, when two were collected (there is another species here of exactly the same colour except that the characteristic rings on the back are missing. This might be taken for a local variety, but in $C$. annulata the gills are laid horizontally, in the other they are vertical, and kept in motion).

Ceratosoma cornigerum Adams and Reeve. Two specimens by Dolfuss, two here in 1936.

Thordisa crosslandi Eliot, another large form not seen again anywhere until one specimen was taken here this year.

None of these species was found by the Cambridge Suez Canal Expedition.

\section{Marine Biological Station, Ghardaqa, \\ Red Sea District. Nov. 30.}

\section{REFERENCES}

Eliot, Sir C., Proc. Zoo. Soc., ii, 354 (1903).

Eliot, Sir C., Proc. Zoo. Soc., i, 380 (1904).

Eliot, Sir C., J. Linn. Soc., 31, 86.

Pruvot-Fol, Mem. Inst. d'Egypte, 89 (1933).

O'Donoghue, Camb. Exped. Suez Canal, Trans. Zool. Soc., 22 (1929). 